\title{
A CASE REPORT OF A SELF-REPRODUCED CASE OF PAEDERUS DERMATITIS
}

Panta Y.R. ${ }^{1}$, Poudyal Y. ${ }^{2}$

\begin{abstract}
Many cases of irritant contact dermatitis are noted every year in the students residing at the Universal College of Medical Science (UCMS) Hostel, Bhairahawa. The exact etiology of the disease was not confirmed but the suspect was an insect 'Paederus', commonly referred to as 'acid fly' in UCMS. However, none of the patients ever gives the clear cut history about the time of contact with the insect after noticing the lesion. So, an experiment was performed by crushing the suspected insect on the skin of the flexor aspect of the forearm and the reactions produced on the skin and the symptoms were noted every 12 hourly till the primary lesion was formed. Erythematous papules were formed initially that passed through different stages to form an erythematous plaque with many vesicles that suppurated to form sterile pustules. This resembled the common lesions observed in the students. It was confirmed that the irritant contact dermatitis observed in the students residing at the UCMS hostel is Paederus dermatitis. The clinical course of this dermatitis was also revealed experimentally.
\end{abstract}

KEY WORDS: Paederus, Acid fly, Dermatitis

1. M.B.B.S. Student, Universal College of Medical Science \& Teaching Hospital, Bhairahawa, Nepal

2. Assistant Professor, Department of Dermatology, Universal College of Medical Science \& Teaching Hospital, Bhairahawa, Nepal

\author{
For Correspondence \\ Mr. Yugesh Raj Panta, \\ M.B.B.S. Student, \\ Universal College of Medical Science \& Teaching Hospital, \\ Bhairahawa, Nepal \\ E-mail:pantayugeshraj@gmail.com
}




\section{INTRODUCTION}

Paederus dermatitis is an irritant contact dermatitis caused by the release of vesicant toxin named 'pederin' contained in the hemolymph of 'paederus' insect (Figure 1), mainly by crushing the insect onto the skin ${ }^{1}$. The primary lesion is vesicle/bulla over an erythematous base that may suppurate to form pustules. Students in the UCMS hostel are commonly affected by this dermatitis. We report a case of Paederus dermatitis that was self reproduced on the skin.

\section{Figure 1: Pederus insects}

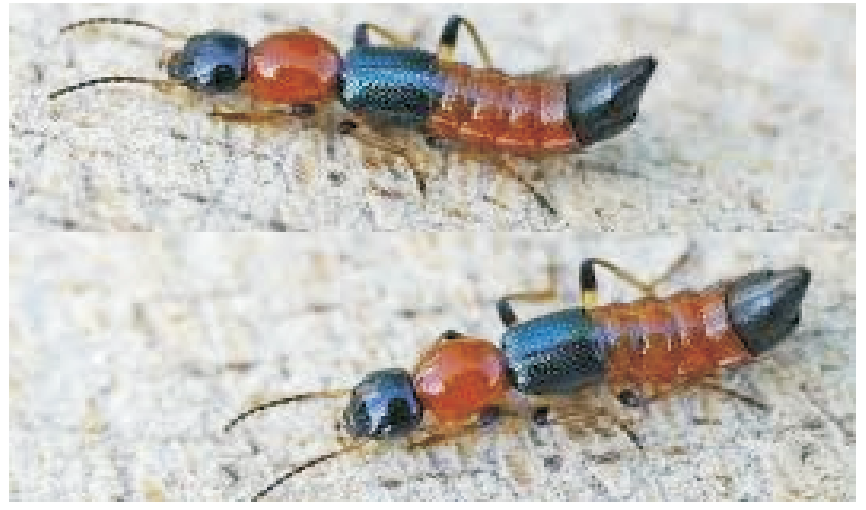

\section{CASE REPORT}

This is a report of a self reproduced case of Paederus dermatitis. A 'Paederus' insect was taken. The insect was crushed onto the flexor aspect of the right forearm to release the toxin-containing hemolymph of the insect. The crushed insect was smeared on the skin and the area marked inside a circle. An ant was also taken and the process was repeated with the ant on the corresponding location of left forearm which was taken as a control.

The reaction in the skin was observed every 12 hourly and noted. The first reaction was observed at 12 hours after the contact which consisted of three erythematous papules inside the marked area (Figure 2). The papules increased in size and number to produce symptoms of slight itching and discomfort at $36^{\text {th }}$ hour(Figure 3 ).

\section{Figure 2: Lesion after $12^{\text {th }}$ hour of contact}

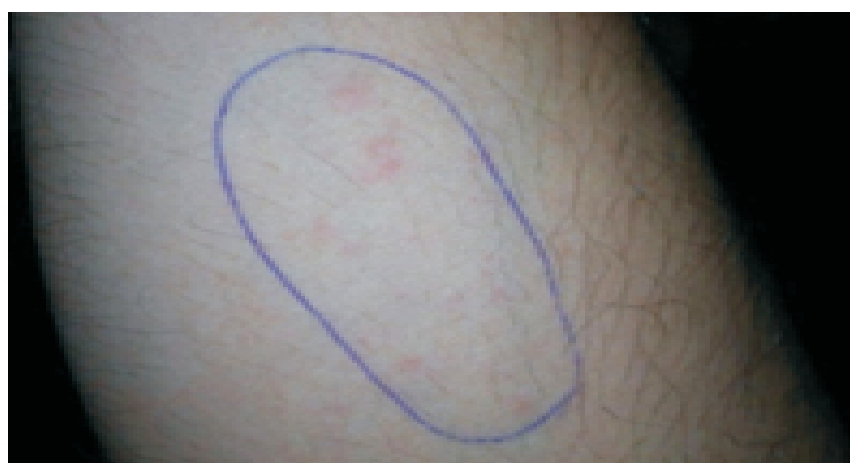

\section{Figure 3: Lesion after $36^{\text {th }}$ hour of contact}

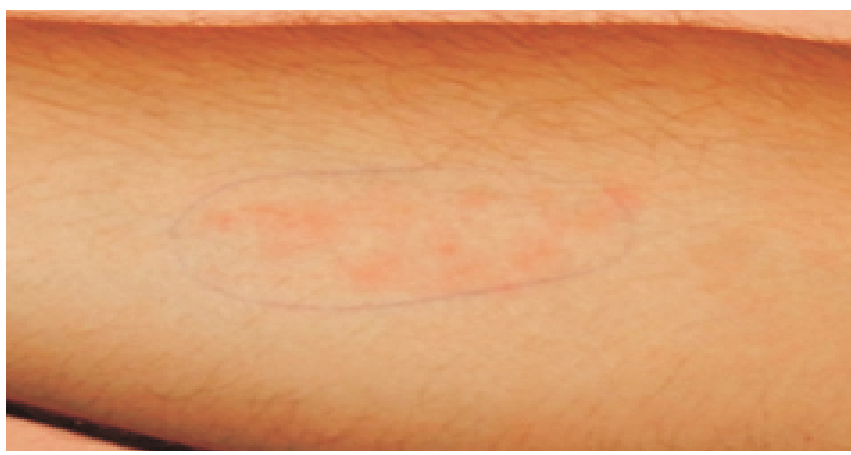

On the third day, small vesicles began to appear over the erythematous papules. The papules became confluent to form irregular plaque with well-defined margin (Figure 4). The vesicles increased in number to produce the symptom of mild burning sensation.

On the $4^{\text {th }}$ day, the vesicles increased in number and size. Some of the vesicles turned into pustules (Figure 5). The symptom was predominantly burning sensation with mild pain.

\section{Figure 4: Lesion on $3^{\text {rd }}$ day after contact}

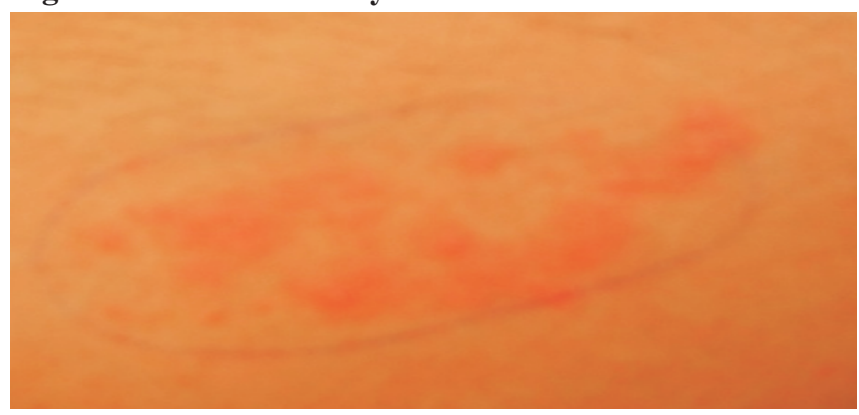

Figure 5: Lesion on $4^{\text {th }}$ day after contact

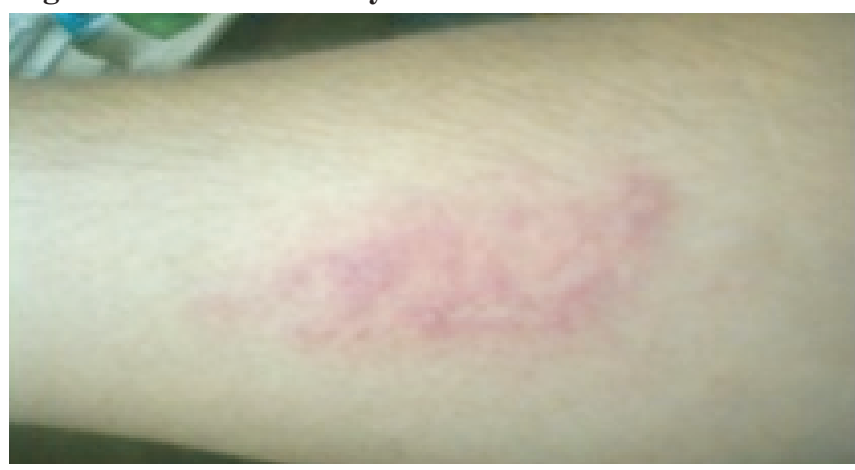

On the $5^{\text {th }}$ day, vesicles continued to grow in number and size. Some of them became confluent to form larger vesicles. Erythema began to appear around the lesion and the site became oedematous (Figure 6). Burning sensation began to resolve and the symptom was dominated by pain. Slight tenderness was observed when pressure was applied at the lesion. 
On the $6^{\text {th }}$ day, pustules increased in size. Some pustules ruptured to form crusts. Both the erythema and oedema increased around the lesion (Figure 7). Pain became more intense and tenderness was present at and around the lesion upto $3 \mathrm{~cm}$ from the margin of the lesion.

These changes continued and became more intense on the $7^{\text {th }}$ day (Figure 8). There was extreme pain and tenderness even on moving the forearm at the elbow joint.

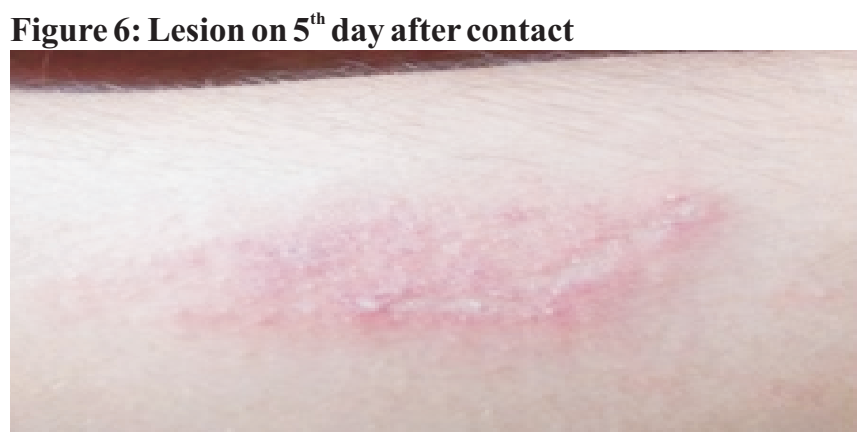

\section{Figure 7: Lesion on $6^{\text {th }}$ day after contact}

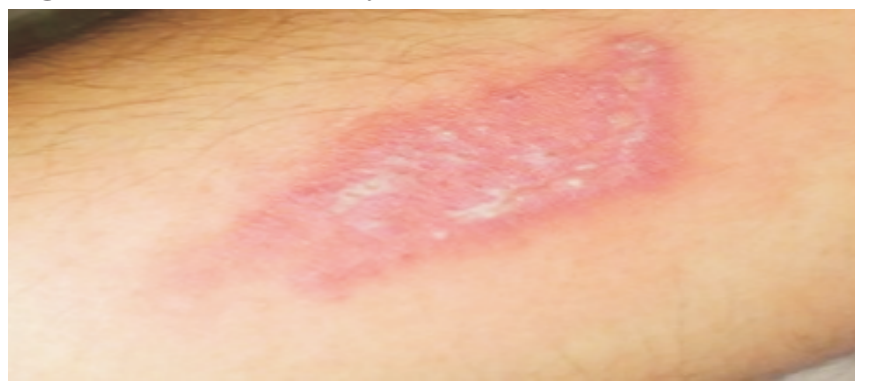

Intervention was done on the $7^{\text {th }}$ day after the expected primary lesion was completely formed. The pus from the pustules was sent for microscopy, culture and sensitivity testing. Treatment in the form of Topical combined antibiotic Neomycin sulphate and steroid Beclomethasone dipropionate applied 2 times a day, Oral antibiotic Azithromycin 500mg OD for 3 days, and oral antihistaminic Loratidine $10 \mathrm{mg}$ OD for 5 days was started. The pus microscopy and culture report showed no bacterial growth. The treatment was continued to full course. The lesion healed with granulation tissue at 1 week. The granulation tissue resolved without scar, leaving behind a brownish patch at the site of lesion (Figure 9).

\section{Figure 8: Typical lesion on $7^{\text {th }}$ day after contact}

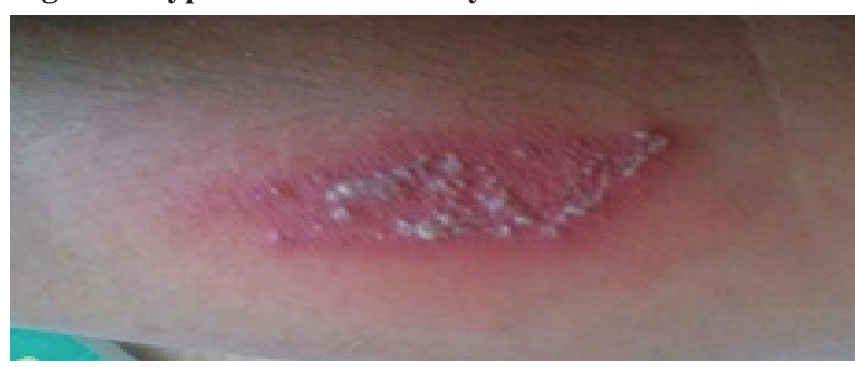

\section{Figure 9: Residual brownish patch after 10 weeks}

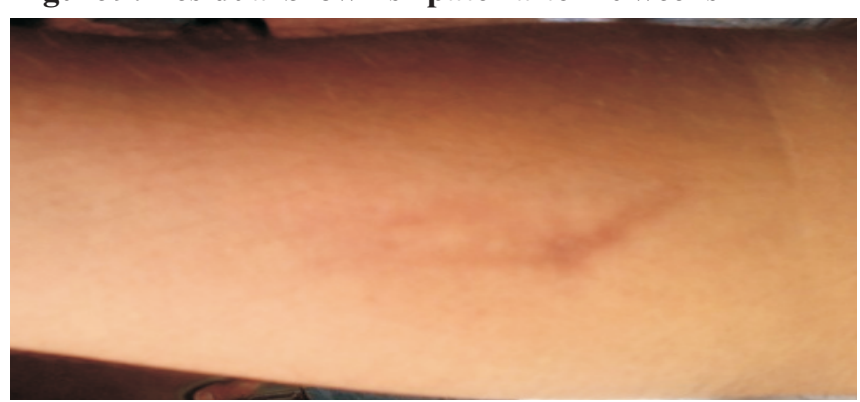

Throughout the observation period, no reaction was noted at the 'control' site.

\section{DISCUSSION}

Paederus dermatitis is an irritant contact dermatitis. It is endemic in many tropical areas. Many outbreaks are reported in the literature from countries like $\operatorname{Iran}^{2}, \mathrm{Iraq}^{3}$, Malaysia ${ }^{4,5}$, China $^{6}$, Srilanka ${ }^{7}$ and India ${ }^{8}$. The outbreaks of Paederus dermatitis occur most commonly at the end of the rainy seasons when the population of the adult insect grows rapidly. Some other examples of outbreaks include the outbreaks in medical mission boat in Amazon ; United Nations Hospital at Koidu Sierra Leone (West Africa) ${ }^{1}$; a primary school at Terengganu, Malaysia ${ }^{4}$; Sri Jayawardanapura General Hospital, Kotte, Sri Lanka ${ }^{7}$; and Manipal University Karnataka ${ }^{8}$. However, no cases are reported from Nepal till now.

The insect responsible for this dermatitis is Paederus by genus of the family Staphylinidae (commonly called as rove beetles or Nairoby fly and named in UCMS hostel as acid fly). Paederus beetles are small, soft bodied and are roughly $1 \mathrm{~cm}$ in length. They are dark orange in color with their head, front wings (elytra) and the tip of their abdomen colored black. The insect breeds in wet rotting leaves and soil (that are found abundantly behind the UCMS hostels). It neither bites nor stings the human beings. The hemolymph of this insect contains a vesicant toxin called Pederin which is considered to be 12 times more poisonous than the cobra venom ${ }^{10}$. Pederin contacts human skin only when a beetle is brushed vigorously over the skin or crushed ${ }^{11}$. This may happen knowingly, or unknowingly especially during sleep that releases this toxin that induces irritant contact dermatitis. The manufacture of pederin is largely confined to adult female beetleslarvae and males only store pederin acquired maternally (i.e., through eggs) or by ingestion. Actually, the toxin is manufactured, not by the beetles themselves, but by endosymbiont bacteria, probably some species of Pseudomonas ${ }^{12}$.

The main pathophysiological changes observed in irritant contact dermatitis are skin-barrier disruption, epidermal 
cellular changes, and cytokine release mainly from keratinocytes. It is a direct cellular damage done by the irritant 'pederin' There is usually an inflammatory response of the skin to exogenous agents, in which inflammatory mediators may be activated but memory T-cell function or antigen-specific immunoglobulins are not involved. Irritants produce various responses on the skin that range from stinging, burning, and tightness to erythema, urticarial reactions, frank eczema, or chemical burns ${ }^{1}$. In addition, Pederin blocks mitosis at levels as low as $1 \mathrm{ng} / \mathrm{ml}$, by inhibiting protein and DNA synthesis without affecting RNA synthesis, prevents cell division and causes skin barrier disruption leading to blister formation ${ }^{13}$. Acantholysis is probably caused by the release of epidermal proteases $^{8}$.

The lesions of Paederus contact dermatitis are usually in the form of a typical bizarre linear vesicles and sterile pustules on an erythematous skin. The lesion appears on the skin about $12-$ 48 hours after contact ${ }^{7}$. Different responses are seen in the skin depending upon its concentration, duration of exposure, and individual characteristics. Mild cases are limited to slight erythema lasting for a couple of days. With moderate cases, the erythema evolves into vesicles and bullae over a few days, after which the blisters dry out over a week leaving hyper- or hypopigmented patches that may last for years. Scarring usually does not occur. Symptoms are limited to little discomfort in mild to moderate cases, unless the area becomes secondarily infected. The lesions are characteristically linear due to smearing of the crushed insect across the skin. Patients may unknowingly transfer the toxin to other areas like genitals and face or the toxin may spread to contagious site through skin apposition to give 'kissing lesions' or 'mirror image lesions' especially over the flexure of the elbow, adjacent surfaces of the thighs etc. Severe cases, in addition to showing more extensive blistering, may demonstrate additional symptoms, such as fever, neuralgia, arthralgia, and vomiting ${ }^{14}$. If the periorbital area is affected, conjunctivitis may develop referred to "Nairobi eye" in eastern Africa. It may even result in intense pain and temporary blindness ${ }^{1}$.

The clinical features of Paederus dermatitis are most commonly confused with phytophotodermatitis ${ }^{9}$. The lesions may also vary to simulate the lesions of herpes simplex, herpes zoster, liquid burns, acute allergic or irritant contact dermatitis and millipede dermatitis ${ }^{8}$.

The characteristic linear appearance of the lesions, their predilection for exposed areas, the presence of kissing lesions, and most importantly epidemiological features (occurrence of similar cases in a given area, the seasonal incidence and identification of the insect) should enable the clinician to arrive at the right diagnosis ${ }^{8}$.
The cases should be managed as irritant contact dermatitisremoval of irritant, initial washing with soap and water, application of cold wet compresses ${ }^{13}$. Once the lesion appears, healing can be achieved faster by administrating a combination of topical steroids and oral antibiotics (ciprofloxacin) and antihistaminic (cetrizine) than with steroids and antihistaminic alone ${ }^{1}$. It is hypothesized that the better response with the antibiotics may be because of the possible contamination of skin by pederin-producing endosymbiont bacteria while crushing the insect ${ }^{1}$.

Paederus dermatitis can be prevented by avoiding the humanbeetle contact. Learning to recognize Paederus beetles and avoiding handling or crushing these insects will help decrease these eruptions. If a beetle lands on the skin, it should be blown off or encouraged to walk onto a piece of paper and then removed. The area in contact should be immediately washed with soap and water, and any clothes in contact with the beetle should be washed as well. Doors should be kept closed and window screening should be kept in good repair to help reduce entry of these insects into buildings. Since beetles are attracted to light, these should be switched off near areas where people sleep. Removal of any decaying vegetation around buildings and work areas helps to eliminate potential harborage for the beetles and their larvae. The application of deltamethrin dust to vegetation may help to reduce beetle numbers in small areas ${ }^{15}$.

\section{CONCLUSION}

With this case report, we want to put emphasis on 'Paederus' insect as the most common cause of irritant contact dermatitis at UCMS hostel. We recommend high suspicion of paederus dermatitis if the typical blisters on erythematous base are seen on people residing at the endemic area. We also want to make the concerned authorities aware about the implementation of possible preventive measures to control Paederus at the UCMS hostel keeping in mind the possible outbreak of Paederus dermatitis.

\section{REFERENCES}

1. Qadir SNR, Raza N, Rahman SB. Paederus dermatitis In Sierra Leone. Dermatology Online Journal 2006; 12 (7): 9.

2. Zargari O, Kimyai-Asadi A, Fathalikhani F, et al. Paederus dermatitis in northern Iran: a report of 156 cases. Int J Dermatol 2003; 42: 608-12.

3. Al-Dhalimi MA. Paederus dermatitis in Najaf province of Iraq. Saudi Med J 2008; 29(10): 1490-93.

4. Rahmah E, Norjaiza MJ. An outbreak of Paederus dermatitis in a primary school, Terengganu, Malaysia. Malays J Pathol 2008, 30: $53-56$ 
5. Mokhtar N, Singh R, Ghazali W. Paederus Dermatitis amongst medical Students in USM. Med J Malaysia 1993; 48(4): 403-06.

6. Huang C, Liu Y, Yang $J$ et al. An outbreak of 268 cases of Paederus dermatitis in a toy-building factory in central China. Int J Dermatol 2009; 48(2): 128-31.

7. Kamaladasa SD, Perera WDH, Weeratunge L. An outbreak of paederus dermatitis in a suburban hospital in Sri Lanka. Int $J$ Dermatol 1997; 36(1): 34-36.

8. Singh G, Yousuf AS. Paederus dermatitis. Indian J Dermatol Venerol Leprol 2007; 73(1): 13-15.

9. Mammino JJ. An Outbreak on a Medical Mission Boat in the Amazon. JClin Aesthet Dermatol 2011; 4(11): 44-46.

10. Huang FC, Chen WJ, Shih MH. Paederus-Induced Keratitis. Cornea 2010; 21: 941-43.
11. Mullen GR, Durden LA. Medical and Veterinary Entomology 2009 edition. Academic Press. 2009. pp94.

12. Piel J. A polyketide synthase-peptide synthetase gene cluster from an uncultured bacterial symbiont of Paederus beetles. Proc Natl Acad Sci USA 2002 Oct; 99(22): 14002-07.

13. Frank JH, Kanamitsu K. Paederus, SensuLato (Coleoptera: Staphylinidae): Natural History and Medical Importance. J Med Entomol 1987; 24 (2): 155-91.

14. Borroni G, Brazzelli V, Rosso R. Pavan M. Paederus fuscipes dermatitis: a histopathological study. Am J Dermatopathol 1991; 13: 467-74

15. Qing-yu M. Effect of Four Kinds of Insecticides on Predatory Function of Paederus fuscipes Curtis. Sichuan journal of zoology 2006. 